\title{
Amalgam, risk, benefits and the precautionary principle
}

\author{
Derek Richards \\ Editor, Evidence-based Dentistry
}

Evidence-Based Dentistry (2008) 9, 2. doi: 10.1038/sj.ebd.6400556

In this issue of Evidence-based Dentistry, we are publishing our first Dental Evidencebased Topic (DEBT) on the use of dental amalgam in children. As we are hoping to develop this feature, I encourage readers to submit articles for this new element of the journal.

The bottom line of the amalgam DEBT is that it is safe to use in children, although current research suggests that resin-modified glass ionomer cements (and compomers) are now showing durability comparable to amalgams, at least for occlusal and moderate sized class II cavities, ${ }^{1}$ with preformed metal crowns showing superiority for larger restorations. $^{2}$

The continuing use of amalgam in dentistry has been challenged for many years because of concerns that its use is associated with a range of conditions such as Alzheimer's, Parkinson's disease and multiple sclerosis. Several reviews in the area have found that current evidence for a role for amalgam in these diseases is inconclusive, however. ${ }^{3-5}$ The latest of these, a preliminary report by the Scientific Committee on Emerging and Newly Identified Health Risks, ${ }^{6}$ concluded that there are no increased risks of adverse systemic effects; the Committee does not therefore consider that the current use of dental amalgam poses a risk of systemic disease.

Even without evidence of any adverse health effects, the Committee on Toxicity of Chemicals in Food UK (COT) advised that it was prudent, where clinically reasonable, to avoid its use in pregnant women. More recently, the Norwegian Government imposed a ban on dental amalgam from 1 January 2008 as part of legislation to prohibit the production, exportation, sale and use of substances that contain mercury. A Professor Emeritus of Biomaterials at
Dalhousie University, Halifax, Canada, writing in a Journal of Dental Research editorial, describes this as a, "bureaucratic travesty" for the following reasons: ${ }^{7}$

- At least $50 \%$ of environmental mercury pollution comes from natural sources.

- Some $42 \%$ of environmental mercury pollution comes from the burning of fossil fuels.

- No valid scientific studies have ever shown that dental amalgam poses a health hazard to patients, to dentists, or to the environment.

He goes on further to calculate, "that the environmental impact of mercury from 800000 dental offices world-wide would represent between 0.04 and $0.20 \%$ of the total world-wide environmental mercury pollution from all sources", pointing out that this would be significantly reduced by the use of amalgam traps.

Although the use of dental amalgam is on the decline, it is still an effective filling material that is longlasting, cost-effective and less technique-sensitive than the majority of the newer dental restorative materials. ${ }^{8,9}$ The COT and Norwegian Government decisions on amalgam are based on the increasingly prevalent use of the precautionary principle, articulated following the 1998 Wingspread Conference (www.sehn.org/wing.html), "When an activity raises threats of harm to human health or the environment, precautionary measures should be taken even if some cause and effect relationships are not fully established scientifically. In this context, the proponent of an activity, rather than the public, should bear the burden of proof. The process of applying the precautionary principle must be open, informed and democratic and must include potentially affected parties. It must also involve an examination of the full range of alternatives, including no action." (www.sehn.org/precaution.html)

Although the COT decision to advise that amalgam use should be avoided in pregnant women is probably justified, it is more difficult to reconcile the Norwegian government's view with their failure to ban some of the larger contributors to environmental mercury pollution. What I do find interesting about that precautionary principle is that it seems just a modern restatement of the risk to benefit balance that scientists have been weighing up for years. What that precautionary principle now does is shift the balance of proof too far. To me, this is a symptom of an increasingly risk-averse society which is generating higher and higher barriers to muchneeded good quality research.

1. Chadwick BL, Evans DJP. Restorations of class II cavities in primary molar teeth with conventional and resin modified glass ionomer cements: a systematic review of the literature. Eur Arch Paed Dent 2007; 8:14-21

2. Attari N, Roberts JF. Restoration of primary teeth with crowns: a systematic review of the literature. Eur Arch Paed Dent 2006; 7:58-63

3. Bates MN. Mercury amalgam dental fillings: an epidemiologic assessment. Int J Env Health 2006; 209:309-316

4. National Health and Medical Research Council, Australia. Dental Amalgam and Mercury in Dentistry. Report of a National Health and Medical Research Council Working Party. 1999.

5. Department of Health. Committee on Toxicity of Chemicals in Food, Consumer Products and the Environment. Statement on the Toxicity of Dental Amalgam. London: Department of Health; 1998.

6. Scientific Committee on Emerging and Newly Identified Health Risks. Preliminary Report on the Safety of Dental Amalgam and Alternative Dental Restoration Materials for Patients and Users. 2007.

7. Jones DW. Has dental amalgam been torpedoed and sunk? J Dent Res 2008; 87:101-102.

8. Downer MC, Azli NA, Bedi R, Moles DR, Setchell DJ. How long do routine dental restorations last? A systematic review. Br Dent J 1999; 187:432-439.

9. National Health Service Centre for Reviews and Dissemination. The Longevity of Dental Restorations: a Systematic Review. CRD Report 19. University of York; 2001. 